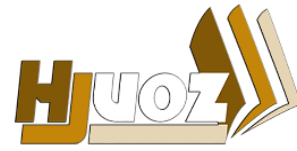

hjuoz.uoz.edu.krd p-ISSN: 2410-7557
كَّوارا زانستيّن مروّقايهتى يا زانكوّيا زاخوّ

مجلة العلوم الانسانية لجامعة زاخو

Humanities Journal of University of Zakho (HJUOZ)

Vol. 5, No. 4, pp. 1125-1136, December-2017

\title{
التفكير ماوراء المعرفة لدى طلبة الجامعة وعلاقته ببعض المتغيرات
}

\author{
محمد سعيل محمد \\ قسم التربية وعلم النفس، كلية التربية الاساسية، جامعة دهوك، اقليم كوردستان - العراق.

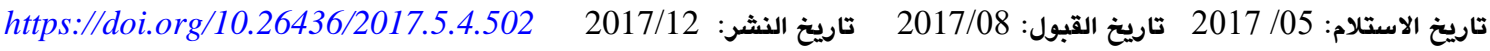

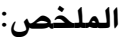

تاتي اهمية البحث من خلال اهمية تعلم مهارات التفكير ماوراء المعرفي لانها تسهم في استخدامها من قبل طلبة الجامعة للبحث والاستقصاء والتدريب لحل المشكلات. وقد استهدف البحث التعرف على مستوى مهارات التفكير ماوراء المعرفي لدى طلبة جامعة دهوك والتعرف على الفروق ذات الدلالة المعنوية في مستويات مهارات التفكير ماوراء المعرفي وفق متغيرات الجنس ( اناث / ذكور ) والتخصص ( علمي/ انساني ). وقد تحدد البحث بطلبة جامعة دهوك للدراسة الصباحية للعام 2015 -2016 واقتصر البحث على عينة طبقية عشوائية بلغت ( 200 ) طالبا وطالبة منهم ( 100 ) طالبا و (100 ) طالبة. اما اداة البحث فقد قام الباحث باعداد مقياس مهارات التفكير ماوراء المعرفي وتكون من ( 42 ) فقرة موزعة على ثلاث مجالات ولكل مجال ( 14 ) فقرة ولكل فقرة ( ثلاث ) بدائل وتم استخراج الصدق والثبات للاداة والذي بلغ ( 0.84 ). وقد تراوحت درجات المقياس بين ( 126 ) درجة كدد اعلى و ( 42 ) ) درجة كدد ادنى

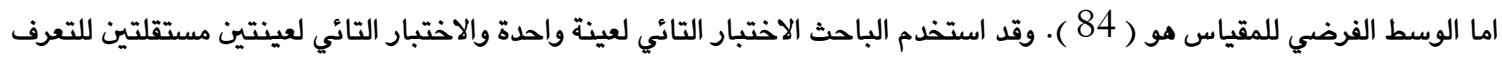
على دلالة الفرقق بين متغيرات البحث تبعا للجنس والتخصص الدراسي ومعامل ارتباط بيرسون لحساب الثبات. ومن ابرذ نتائج البحث ان طلبة جامعة دموك يتميزون بالوعي فيما يخص بمهارات التفكير ماوراء المعرفي. والطلاب في العلوم الانسانية يستخدمون مهارات التفكير ماوراء المعرفي افضل من الطلالبات في حين ان الطالبات في الاقسام العلمية يستخدمن مهارات التفكير ماوراء المعرفي افضل من

الطلاب. كما اثار البحث الى الحاجة لمزيد من البحوث للكشف عن العوامل المؤثرة في تباين الدرجات لدى الطلبة. الكلمات الدالة: المهارة، التفكير، ماوراء المعرفة، حل المشكلات.

الحياة المعاصرة يجعل من الصعب مواكبة المستجدات الصديثة لذا فهو بحاجة الى اتباع اساليب تعلم فعالة لتمكن من استيعاب الكم الهائل من المعلومات وتجهيزها ومعالجتها واستدعائها عند الحاجة والضرورة (ردادي ، 2002،35) وان هدف التربية كما يرى بياجيه هو ايجاد متعلمين يتمكنون من عمل اثياء جديدة وليس اعادة الاثياء القديمة التي قامت بها الاجيال السابقة وتشكيل العقول التي لاتقبل كل شيء يقدم لهم دون تمحيص وتحليل ( عبدالستار، 195، 1911). ان الطلبة الذين يستخدمون استيراتيجيات ماوراء المعرفة بفعالية يكونون على وعي بسلوكياتهم الخاصة ومدركون لتفكيرهم عندما يقومون باداء مهمة معينة ويمكنهم من استعمال هذا الوعي في السيطرة على مايفعلونه والتحكم فيه ويجب على المدرسين ان يساعدوا طلبتهم على ان يتعلموا استيراتيجيات ماوراء المعرفة من خلال مساعدة الطلبة على التخطيط ويجعل الطلبة اكثر نشاطا ومن ثم تحسين اداهمويساعدهم على النجاح الاكاديمي ويزودهم بالتقنيات التي تدفعهم الى الاستغلال ثم اكتساب المعرفة واداء المهام بنجاح (العيسوي

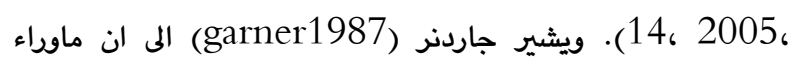

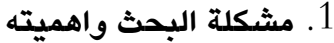

ان الاهتمام بالفرد المنتج القادر على مواجهة مشكلات الحياة العصرية اصبح امرا مهما والشباب القادر على حل مشكلاته يعد احد عوامل تقدم المجتمع وسلامته والمجتمع بحاجة الى فكر متفتح قادر على تقديم الحلول المبتكرة واستخدام الاساليب والاجراءات الفعالة النشطة.والشباب ثروة المجتمع فهم الذين يتحملون مسؤولية التنمية الاجتماعية والاقتصادية في مجتمعاتهم وهم بحاجة الى توجيه ورعاية ويخاصة في مرحلة الجامعة.( دسوقي، 379، 1990) وقد اتفق الكثير من علماء النفس المعرفي على ان التحدي الحقيقي الذي يواجهونه اليوم يتمثل في مدى امكانية الاهتمام بالذاكرة الانسانية من حيث فاعليتها وسعة استيعابها وكفاءة نظم و عمليات تجهيز المعلومات من خلال تفعيل دور الاستيراتيجيات المعرفية كضرورة حتمية لمواجهة الانفجار الهائل للمعلومات وزيادة اعداد الطلبة بالجامعة.(سيد والشريف ،299،1999).ويمثل التعلم المظهر الرئيسي في الحياة البشرية المتحضرة اذ يعبر عن نشاطهم العقلي ولابد للمتعلم اتباع اساليب منطقية في عملية التعلم ومن جهة اخرى فان التقدم العلمي الذي تشهده 
الاستيراتيجيات والمهارات المعرفية وخاصة مهارات التفكير ماوراء المعرفة وضرورة التعرف على علاقة هذه المهارات والاستيراتيجيات مع بعض المتغيرات لدى طلبة الجامعة والتي تشمل المرحلة الدراسية ونوع الدراسة وكذلك جنس الطلبة وهذا هو مضمون ومشكلة البحث الحالي لان ذلك يساعد الطلبة على التعامل الايجابي مع زملائهم ومدرسيهم مما يزيد من فعالية تعلمهم وتوظيف تلك المهارات المعرفية بفعالية في حل مشكلاتهم.

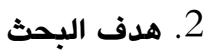

يهدف البحث الحالي الى التعرف على : 1. مستويات مهارات التفكير ماوراء المعرفة لدى طلبة جامعة دهوك 2. الفرق ذات الدلالة المعنوية في مستويات مهارات التفكير ماوراء المعرفة وفق متغيرات

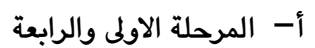

$$
\begin{aligned}
& \text { ب- التخصص الدراسي (علمي - انساني ) } \\
& \text { ت- الجنس ( ذكور - اناث ) }
\end{aligned}
$$

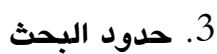

يتحدد البحث بطلبة جامعة دهوك للدراسات الصباحية التخصصات العلمية والانسانية وللجنس الذكور والاناث للعام الدراسي 20152016

4. تصديد المصطلحات

1.4. التفكير ماوراء المعرفة: عرفه كل من

أ- اندرسون(Anderson 2002) العين الثالثة التي تنشغل في المراقبة المستمرة للاستيعاب(العتوم واخرن ، 2007 269) ب- ارثر كوستا وبيناكاليك 2003 التفكير حول التفكير وهذا يحدث في القشرة الدماغية للفرد ويعبر عن مقدرتنا على معرفة مانعرف ومالانعرف(ابو جادو و نوفل ،2013 (344،

ت- القضاة والترتوري 2006 هو عمليات تحتم علينا وظيفتها التخطيط والمراقبة والتقييم لاداء الفرد في حل المشكلة او الموضوع) القضاه والترتوري ، 2006 ، 325). ث- عبيد 2009 تأملات عن المعرفة او التفكير فيما يفكر وكيف يفكر

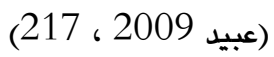
2.4. مهارات التفكير ماوراء المعرفة

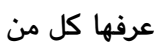
أ- ستيرنبرج (Sternberg 1985) مي من اهم مكونات السلوك

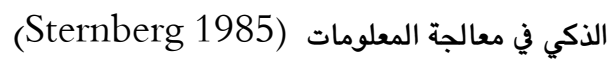

المعرفة هو في الاساس معرفة ماالمعرفة فاذا كانت المعرفة تتضمن الادراك والفهم والتذكر فان ماوراء المعرفة يمكن تصنيفه بانه ماوراء الادراك وماوراء الفهم والذاكرة ويبقى مصطلح ماوراء المعرفة في المرتبة العليا (الشرقاوي ، 2003 ،206 ) ان عمليات ماوراء المعرفة من اهم المتغيرات المعرفية فهو الحجر الاساس في تنمية القدرات العقلية لدى الفرد ويساعده على ادراك العمليات العقلية والمعرفية التي يقوم بها الفرد خلال التعلم والتحكم فيها واختيار انسب استيراتيجيات التعلم لاستخدامها في المواقف التعليمية التي يمر بها مما يؤدي به الى تعلم اكثر فعالية بالطريقة التي تناسب تفكيره .(عفيفي ، 2006 ، 1) وتتضح اهمية تعلم مهارات التفكير ماوراء المعرفة بالنسبة للطلبة في انها تسهم في استخدامهم لاساليب البحث والاستقصاء والتدريب على مهلى ماءراء حل المشكلات والاكثار من استخدام الاسئلة المفتوحة التي تعين على ممارسة التفكير وتوفير اكبر قدر ممكن من المعارف والمعلومات وتدريب الطلبة على التاني في اصدار الاحكام وتوفير اكبر قدر ممكن من البدائل التي يستطيع الطالب التعامل معها (حميدة، 2010 ، 1). ان مهارات التفكير ماوراء المعرفة يساعد المتعلم على زيادة وعيه ويساعده كذلك على التعرف على مواطن قوته ليدعمها ومواطن ضعيفة فيعالجها وان تنمية مهارات التفكير والمعرفة يتطلب استخدام ممارسات مختلفة في عملية التعلم لمساعدة المتعلمين على التخطيط والمراقبة والتقييم فيما يقومون به من اعمال ة وانشطة تعليمية ممايساعدهم على تحمل مسؤولية تعلمهم ويؤدي الى زيادة وعي المتعلمين مما

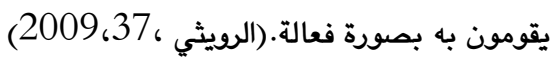
وقد تم استخدام مصطلح ماوراء المعرفة في الادب التربوي ليشير الى بلى بهوري المعرفة عن الادراك وتنظيمه كما انه يعبر عن وعي الفرد التام ومافيه من تيقظ واحساس بالخطوات التي يقوم بها الفرد في اثناء عملية التعلم.(الحمودي واحمد ،2011 ، 2142).وقد دخل مفهوم ماوراء المعرفة في مجال علم النفس المعرفي على يد (JOHN Flavell) جون فلافيل في منتصف السبعينات من القن الماضي ( العتوم ،2014 ،207) وقد لاحظ فلافيل ان الافراد يقومون بعملية مراجعة لفهمهم الخاص والانشطة المعرفية الاخرى وتقودمم الى اختيار وتقويم المهام المعرفية والاهداف والاستيراتيجيات التي يمكن ان تنظم تعلمه

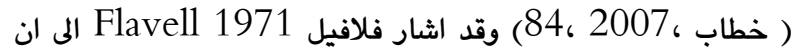
مفهوم ماوراء المعرفة يتعلق بالمعرفة وادراكها ويصف الافكار ماوراء المعرفة بانها مخططة وموجهة نحو هدف وقصد وهي سلوكيات عقلية تهدف الى انجاز المهام والمهارات المعرفية التي تعبر عن وعي الفرد بذاته مما يجعل الفرد فعالا وايجابيا في بيئته وتبرز اممية البحث الحالي الى اهمية مهارات التفكير ماوراء المعرفة بوصفها احدى الاهداف الرئيسيةوضرورة الاهتمام بها لدى طلبة الجامعة وان عملية رعاية الطلبة من ضروريات المجتمع لان ذلك يساعد على تحسين تماسك المجتمع وقوته فالاساليب التعليمية المعاصرة بحاجة الى مزيد من من من من 
تسمى بما وراء المعرفة او التفكير ماوراء المعرفي ( المساعيد ، 2008 . 85 ،

واستمر فلافيل (1987 ) في سعيه للكشف عن مفهوم ماوراء المعرفة اذ ركزت دراساته الاولى على تحسين قدرة الاطفال على التذكر وذلك من خلال العمل على مساعدتهم في التفكير في المهمات التي يواجهونها ومن ثم توظيف الاستراتيجيات التي من شانها تطوير عملية التذكر لديهم ، ويعد التفكير ماوراء المعرفة من اكثر موضوعات علم النفس المعرفي

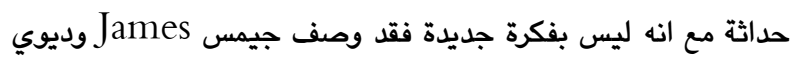
Dewey الشعور في عملية التعلم والتفكير ( ابو جادو ونوفل ، 2010، 343 ) ). وتشير معظم البحوث والدراسات الى ان ماوراء المعرفة تتضمن جانبا تنظيميا ذاتيا للمتعلم فالاطفال الذين يمتلكون مهارات مرتفعة لما وراء المعرفة هم اكثر فعالية في تنظيم تعلمهم ولديهم القدرة على ضبط عمليات التعلم وكذلك القدرة على التوافق والانسجام في مواقف الحياة المختلفة ومن الدراسات مااكد عليه مارس 1998 Harris من خلات التوال دراسة قام بها بان هناك ارتباطا موجبا بين وعي التلاميذ بما يقومون به ويستخدمونه من استراتيجيات ماوراء المعرفة ومدى ادراكهم واستيعابهم للمعلومات والبيانات وقدرتهم على توظيفها واستخدامها في مواقف التعلم المختلفة ( عفانة ونشوان ، 2010 و 2 ، 2 ).

1.1.5. مكونات ماوراء المعرفة: قسم عمليات ماوراء المعرفة الى نوعين هما :

1- عمليات ماوراء المعرفة التي هي مهارات تستخدم لضبط عملية معالجة المعلومات لدى الفرد. 2- عمليات معرفية والتي هي مهارات غير تنفيذية وتستخدم لتوظيف الاستراتيجيات في العمل على المهمة وتتضمن : ا- التخطيط :وهي النقلة في تنفيذ الاستراتيجيات ب - المراقبة: وهي فعالية خطوات الفرد في استخدام الاستيراجيات ج - الاختبار : وهي استراتيجية الفرد عند ادائها د - المراقبة : وهي استراتيجية الفرد كلما دعت الحاجة ه- التقييم : وهي استراتيجية الفرد من اجل تحديد فاعليتها

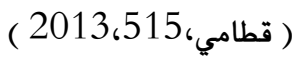
ويصنف جروان 1999 التفكير ماوراء المعرفي كنوع من انواع التفكير المركب وتضم خمسة انواع من التفكير وهي : 1 التفكير الناقد Critical Thinking Creative Thinking التفكير الابداعي النفير 3- حل المشكلات

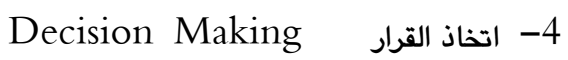
5etacognitive Thinking التفكير فوق المعريف التفراد

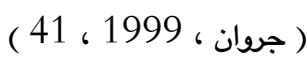

ب- مانلي (Hanly1995) وعي الفرد بمعرفة ادراكه الذي يترافق مع ضبط العمليات المعرفية وتحسينها وربط عناصر التفكير للوصول الى هدف معين (Hanly, 1995,69) ت- كيركل (kirkill 1996 )وعي الفرد بما لديه من قدرات ووسائل ومصادر يحتاج اليها لاداء المهام المكلف بها بفاعلية اكثر وتدقيق نتائج اكثر نجاحاً. (يوسف ، 2011 ، 2012 (372) 1.2.4. التعريف النظري للباحث: وعي الفرد بما لديه من معلومات وكيفية استخدامها في تحقيق اهدافه وتتضمن كيفية التخطيط والمراقبة والتقييم وتوظيفها بما يحقق دقة احكامه في اتخاذ قراراته.

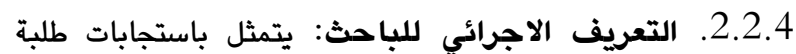
الجامعة على مقياس مهارات التفكير ماوراء المعرفة الذي اعده الباحث معبرا عنها بالدرجة التي يحصل عليها الطلبة على فقرات المقياس. 5. الاطار النظري والدراسات السابقة

$$
\text { 1.5. - اوراء المعرفة }
$$

حظي مفهوم ماوراء المعرفة ( Metacognition ) على اهتمام العديد من الباحثين من ميادين علم النفس لكنه ظهر بشكل واضح على

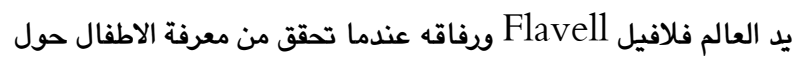
معرفتهم. وقد اصبح ماوراء المعرفة مفهوم شامل عن كل معرفة او عمليات معرفية يمكن ان تشير الى المتابعة او التحكم باي شكل من اثكال المعرفة لذلك فان ماوراء المعرفة هي اللب الرئيس للعديد من بن باني

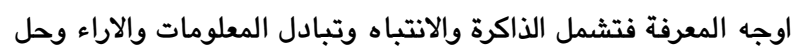

المشاكل والذكاء وغيرها (Moses \& Baird 19996, 75) وتطور مفهوم ماوراء المعرفة منذ ظهوره على فلافل الذي اشار الى انه

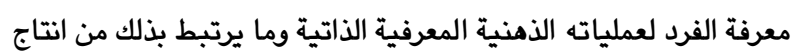
معرفي. (Flavell , 1976,233). وقد الشار براون (Brown ) بان ماوراء المعرفة يشير الى وعي الفرد بعملية التفكير التي يمارسها خلال التعلم وقدرته على السيطرة على بلى نشاطه التعليمي (Brown\& Barclay ,1976,76). غير ان باركنز (perkins) اشار الى ان ماوراء المعرفة هو اهتمام الافراد بمعرفتهم وكيف يفكرون ويتعلمون كما اشار الى كيفية عمل

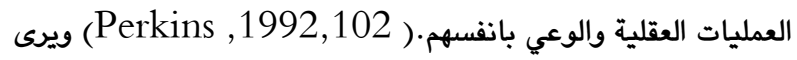

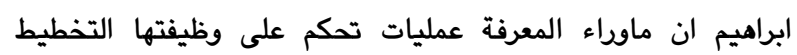
والمراقبة والتقويم لاداء الفرد في حل المشكلات وفي كيفية توجيه مهارات التفكير وادارتها وهي احدى مكونات معالجة المعلومات.(ابراهيم ، 809 ، 2004، 809 ويؤكد (Livingston 1977 ) ان عمليات التفكير المعقدة التي يستخدمها المتعلم تتضمن التخطيط ( planning) للمهمة التي يريد تعلمها ومراقبة استيعابه (monoitoringcomperhesion) للمادة الدراسية وتقويم التقدم ( Evaluation progress )لديه 
2.5 الدراسات السابقة 1- دراسة سيد والشريف 1999 : مدفت الدراسة التعرف على مكونات ماوراء الذاكرة واثرها في التحصيل والتعرف على الفرق بين الاستراتيجيات تبعا للتخصص ويلغت عينة البحث 172 طالبا وطالبة من كلية التربية في جامعة اسيوط تم استخدام قائمة ماوراء الذاكرة واستراتيجيات التذكر وياستخدام معامل ارتباط بيرسون والاختبار التائي لعينة واحدة ولعينتين وتحليل التباين اظهرت النتائج الى وجود علاقة ارتباطية دالة احصائيا بين متغيرات الدراسة والتحصيل لدى ولى ولينين الطلبة كما تميز الطلاب ذوي التحصيل الاكاديمي المرتفع باستخدامهم مهارات ماوراء الذاكرة واستراتيجيات التذكر مقارنة بالطلاب ذوي التحصيل المنخفض. 2- دراسة المزروع 2005 : مدفت الدراسة الى التعرف على مدى فاعلية استراتيجية شكل البيت الدائري في تنمية مهارات التفكير ماوراء المعرفي لدى طالبات المرحلة الثانوية في المملكة العربية السعودية وتكونت عينة البحث من مجموعة طالبات المرحلة الاعدادية وتكونت ادوات البحث من مقياس مهارات ماوراء المعرفة المتكون من (38 ) فقرة ولها ثلاث بدائل وتوزعت الفقرات على مجالات المعرفة التقديرية

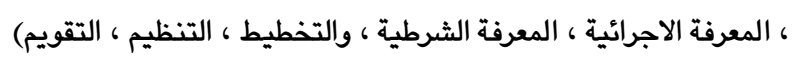
اما الوسائل الاحصائية فقد استخدم معادلة سبيرمان براون ومعادلة كودر ريتشاردسون والفا كرونباخ واظهرت النتائج فاعلية استيراتيجية الشكل الدائري في تنمية مهارات التفكير ماوراء المعرفة لدى الطالبات. 3- دراسة عفيفي 2006 : هدفت الدراسة على التعرف على العلاقة بين مكونات ماوراء المعرفة والتوجهات الدافعية والتحصيل الدراسي والفروق في كل من مكونات ماوراء الذاكرة والدافعية بين طالبات مرتفعة

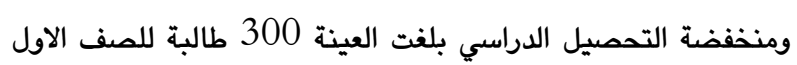
الثانوي لمدارس محافظة الاسماعيلية وتم استخدام مقياس ماوراء الذاكرة ومقياس التوجهات الدافعية في التعلم ولتحقيق هدف البحث ثم استخدام معامل ارتباط بيرسون والانحدار المتعدد وظهرت النتائج وجود علاقة ارتباطية دالة احصائيا بين كل من مكونات ماوراء الذاكرة والتوجهات المعرفية كما اظهرت النتائج وجود فروق دالة احصائيا بين الطالبات مرتفعة ومنخفضة التحصيل الدراسي في مكونات ماوراء الذاكرة والدافعية لصالح الطالبات مرتفعة التحصيل. 4- دراسة الخلي 2008 : مدفت الدراسة الى فعالية برنامج حل المشكلات في تنمية مهارات ماوراء المعرفة وتمثلت المهارات في( هات

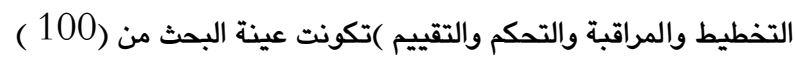
طالبة من طالبات الصف السابع الاساسي من مدارس مدينة تعز في اليمن. تم استخدام مقياس لمهارات التفكير ماوراء المعرفة تكونت من من من مديات 46 فقرة واستعملت الباحثة معامل ارتباط بيرسون واختبار t.test لعينتين مستقلتين ولعينة مترابطة كوسائل احصائية لتحقيق نتائج

\subsection{5 مهارات التفكير ماوراء المعرفة}

مناك اجماع من الباحثين على وجود ثلاث مهارات رئيسة للتفكير

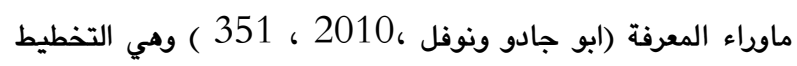
والمراقبة والتحكم والتقييم وهذه المهارات هي المعتمدة في البحث

: Planning التخطيط

وهي وسيلة للتنظيم باسلوب منطقي للعناصر التي ترتبط بالموضوع

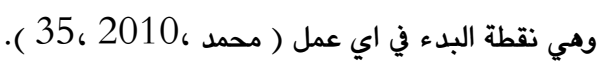
والتخطيط يعني ان هناك للفرد هدفا يسعى ا لتحقيق من خلال خطة

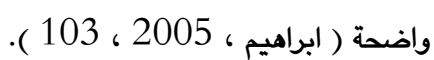

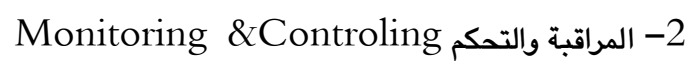
وتشير الى قدرة الاستيعاب لقواعد التعلم وتشير كذلك الى العمليات الذهنية الداخلية للسيطرة والمراقبة وضبط الوعي في اثناء عملية التنفيذ (اسماعيل ، 2013 ، 244 ). 3- Evaluation : التقييم التيميل وهو ضروري لاتخاذ القرار على صحة عملية التعلم وتزويد المتعلم بمستوى ادائه ونجاحه وتزويد المتعلم بمعلومات تساعده على تطوير نفسه وانشطته (اسماعيل ، 2013، 247 ) ). وعلى الرغم مما تقدم بخصوص مهارات التفكي ماوراء المعرفي وما تفرع عنها من مهارات فرعية هناك من الباحثين من ذهب الى اضافة بعد مهد مهات

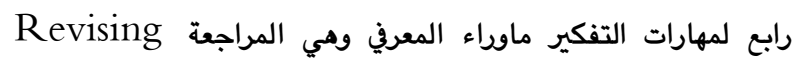
وتتضمن هذه الخطوة مقارنة الهدف المنشود بما تحقق منه بالواقع ماتع ورئ ومقارنة النتائج التي حققها الفرد بالتي توقعها مسبقا.

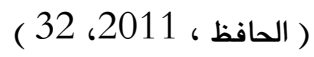
3.1.5. اهمية مهارات التفكير ماوراء المعرفة: لقد زاد الاهتمام بمهارات التفكير فوق المعرفي واصبح تدريسها بؤرة الاهتمام من قبل التربويين وقد يعود ذلك الى مايأتي : 1- اشارت النظرية المعرفية للذكاء الى ان القدرة على الذكاء قابل للتعديل. 2- المدخل البنائي في عملية التعلم والذي يؤكد على نشاط الفرد واستغلال بنائهم المعرفي والتنسيق في ايجاد علاقات في الخبرة المعرفية لدى المتعلمين. 3- منظور معالجة المعلومات والذي يتعامل مع اكتساب المعلومات وتوسيعها وتنظيمها (النجدي واخرون ،2005، وتوسئل 486 ) ان للتعلم ماوراء المعرفة اهمية قصوى في مجال التعلم والعمل فهي تجعل لدى الفرد المقدرة على النجاح وتزيد من ثقته بنفسه وقدراته

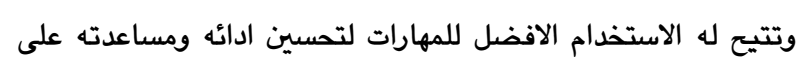
نقل خبراته الى مجالات اخرى في العمل وتزود المهارات بمفاتيح لتحسين تكيفه وتنظيم سلوكه ( العتوم واخرون، 2013 ،276 ). 
التجريبية والضابطة في اختبار مهارات التفكير ماوراء المعرفي لصالح المجموعة التجريبية 9- دراسة السبعاوي 2013 : هدفت الدراسة الى التعرف على اثر استراتيجية التساؤل الذاتي في تنمية مهارات التفكير ماوراء المعرفي لدى تلاميذ المرحلة الابتدائية.تكونت عينة البحث من 68 تلميذا واستعمل الباحث اداة تمثلت بمقياس مهارات التفكير ماوراء المعرفي وتكونت من 49 فقرة ويعد جمع البيانات وتصحيحها وتحليلها احصائيا باستعمال الاختبار التائي لعينتين مستقلتين اظهرت النتائج وجود فروق ذات دلالة احصائية بين متوسط درجات المجموعة التجريبية والمجموعة الضابطة في اختبار مهارات التفكير ماوراء المعرفي ولصالح المجموعة التجريبية التي درست وفق استراتيجية التساؤل الذاتي.

1.2.5. مؤشرات ودلالات من الدراسات السابقة

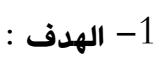

لقد تنوعت اهداف الدراسات السابقة في موضوع ماوراء المعرفة وذلك لتباين متغيرات الدراسة التي تم بحثها فمنها ماهدفت الى فعالية برنامج في تنمية مهارات ماوراء المعرفة كما في دراسة الخلي 2008 وعثامنة

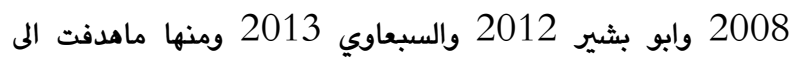
التعرف على مكونات ماوراء المعرفة واثرها في بعض المتغيرات مثل دراسة سيد والشريف 1999 والجراح 2011 اما دراسة عفيفي 2006 فقد هدفت على التعرف على العلاقة بين مكونات ماوراء المعرفة والدافعية ، اما في هذه الدراسة فقد هدف البحث الى التعرف على مستوى التفكير ماوراء المعرفة وعلاقتها ببعض المتغيرات لدى طلبة الجامعة. 2تباين حجم العينة في الدراسات السابقة وقد تراوح اعدادها بي ( 681102 ) فردا ففي دراسة عثامنة والسبعاوي بلغت حجم عينة البحث

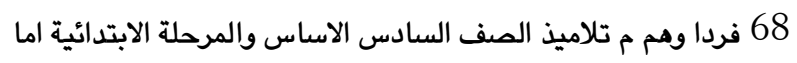
في دراسة الجراح فقد بلفت حجم العينة 1102 في المرحلة الجامعية اما في دراسة الخلي فقد بلفت حجم العينة 100 طالب للصف السابع الاساس بينما في دراسة سيد والشريف فكان حجم العينة 172 طالبا وطالبة في المرحلة الجامعية وفي دراسة عثامنة بلغت جم العينة 300 طالبة للمرحلة الثانوية وفي دراسة ابو بشير بلغت حجم العينة 104 طالبة في الصف التاسع الاساس اما في مذه الدراسة فقد بلغت حجم العينة (200 ) طالبا وطالبة في

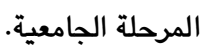

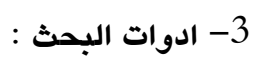
تنوعت ادوات البحث في الدراسات السابقة المستخدمة في قياس ماوراء المعرفة او تنمية مهارات التفكير ماوراء المعرفة او الذاكرة. فقد استخدمت بعض الدراسات في قياسها ادواتا جامزة في حين قامت دراسات اخرى ببناء واعداد ادوات لقياسها اما البحث الحالي فقد تحدد
البحث.واشارت النتائج الى وجود نتائج ايجابية في اختيار قياس مهارات التفكير ماوراء المعرفي باستخدام برنامج حل المشكلات. 5- دراسة عثامنة 2008 : مدفت الدراسة الى كشف اثر برنامج براءميج تدريبي مستندا الى مهارات التفكير ماوراء المعرفي لدى تلميذات الصف السادس الاساسي في مدارس مديرية تربية اربد في الاردن تكونت عينة

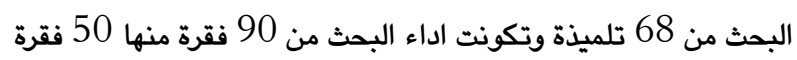
للتذكر السمعي و40 فقرة للتذكر البصري ويعد انتهاء البرنامج والمكون من 18 جلسة تدريبية معتمدا على مهارات التفكير ماوراء المعرفي (التخطيط والمراقبة والتقييم ) ، واشارت النتائج باستخدام اختبار t.test وسيلة احصائية الى فعالية البرنامج وضرورة الامتمام بمهارات التفكير ماوراء المعرفي. 6- دراسة الجراح 2011 : هدفت الدراسة الى التعرف على مستوى التفكير ماوراء المعرفي لدى طلبة جامعة اليرموك في ضوء متغيرات الجنس والتخصص والمرحلة الدراسية وتكونت عينة الدراسة من

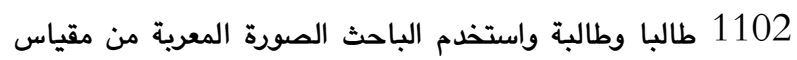
التفكير ماوراء المعرفة (Schraw\& Dennison 1994) واظهرت النتائج حصول افراد العينة على مستوى مرتفع من التفكير مارواء ماوراء المعرفة على المقياس ،كما كشفت الدراسة الى وجود اثر ذي دلالة احصائية في مستوى التفكير ماوراء المعرفي لمعالجة المعلومات وتنظيم المعرفة لصالح الاناث وكانت النتائج لصالح ذوي التحصيل المرتفع كما اظهرت النتائج ان مستوى التفكيرماوراء المعرفي لصالح التخصصات الانسانية. 7- دراسة ابو بشير 2012 : مدفت الدراسة الى التعرف على اثر استخدام استراتيجيات ماوراء المعرفة في تنمية التفكير التاملي لدى تلاميذ الصف التاسع الاساسي تكونت عينة البحث من 104 تلامذة اما ادوات البحث فكانت قائمة من مهارات التفكير التاملي المناسبة لتلامذة الصف التاسع الاساسي واستعملت الباحثة معادلة جتمان ومعادلة كودريتشاردسون 21 واختبار t.test واشارت نتائج البحث الى وجود فروق ذات دلالة احصائية بين متوسط درجات المجموعة

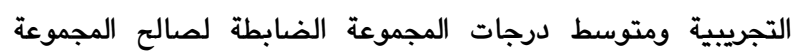

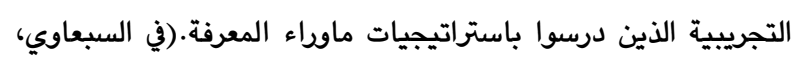
. 76 ، 2013 8- دراسة العلوي 2012 : مدفت الدراسة الى التعرف على اثر استراتيجية التدريس التبادلي في التحصيل وتنمية مهارات التفكير ماوراء المعرفي لدى طالبات الصف الرابع الادبي وتكونت عينة البحث من 63 طالبة وتبنت الباحثة مقياس (شرو ودنسون 1994 ) ترجمة عبيدات وجراح 2011 اداتا لبحثها واستعملت الاختبار التائي لعينتين مستقلتين ومعامل ارتباط بيرسون لتحقيق نتائج البحث واشارت النتائج الى وجود فروق ذات دلالة احصائية بين متوسط درجات المجموعة 
صياغة هدف الدراسة وحدود الدراسة والاطلاع على مقاييس هذه الدراسات واختيار العينة المناسبة والوسائل الاحصائية المناسبة وكيفية عرض النتائج ومناقشتها 6. إبتمع البحث ومينته

يشمل مجتمع البحث الحالي طلبة جامعة دهوك للدراسة الصباحية للعام الدراسي 2015-2016 من الذكور والاناث وللاختصاصات العلمية والانسانية. وقد بلغ عدد الطلبة في كليات جامعة دهوك ( 2015- 2016 ) منهم (5374 ) طالبا و (200) طالبة وقد بلغ عينة البحث ( 100 ) طالبا وطالبة منهم ( 100 ) طالبا وطالبة للتخصص الانساني في كليتي الاداب والتربية الاساس القسم الانساني اما عدد الطلبة للتخصص العلمي فقد بلغ ايضا ( 100 ) طالبا وطالبة في كليتي العلوم والتربية الاساس القسم العلمي وقد ثم اختيار عينة البحث بالطريقة الطبقية العشوائية موزعين بحسب متغيرات التخصص الدراسي ( علمي ، انساني ) والجنس ( ذكور ، اناث ) والجدول ( 1 ) يوضح ذلك.
باعداد مقياس مهارات التفكير ماوراء المعرفة مكونة من ( 42 ) فقرة

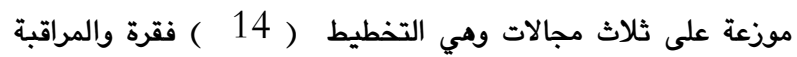

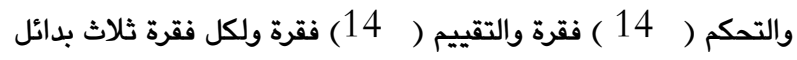
تنطبق بدرجة عالية - تنطبق بدرجة متوسطة - وتنطبق بدرجة ضعيفة. وهي من اعداد الباحث. 4- الوسائل الاحصائية اختلفت الدراسات السابقة في استخدامها للوسائل الاحصائية كل حسب الاهداف والمقاييس المستخدمة وكان من ابرز مذه الوسائل هي (الاختبار التائي لعينة واحدة ولعينتين مستقلتين - معامل ارتباط بيرسون -تحليل التباين-الانحدار المتعدد- معادلة جتمان ومعادلة كيودريتشاردسون 21) اما البحث الحالي فقد استخدم الاختبار التائي لعينة واحدة ولعينتين مستقلتين ومعامل ارتباط بيرسون ) 2.2.5. مدى الاستفادة من الدراسات السابقة بعد عرض الدراسات السابقة حول مهارات التفكير ماوراء المعرفة تم الاستفادة من بعض الاجراءات من حيث صياغة المشكلة وييان اهمية جدول ( 1 ) ): عينة البحث بحسب التخصص الدراسي والجنس انديك

\begin{tabular}{|c|c|c|c|c|}
\hline \multirow{2}{*}{ المجموع } & & الجنس & \multirow{2}{*}{ الكلية } & \multirow{2}{*}{ التخصص } \\
\hline & اناث & ذكور & & \\
\hline 50 & 25 & 25 & الاداب & \multirow{2}{*}{ الانساني } \\
\hline 50 & 25 & 25 & التربية الاساس & \\
\hline 50 & 25 & 25 & العلوم & \multirow[b]{2}{*}{ العلمي } \\
\hline 50 & 25 & 25 & التربية الاساس & \\
\hline 200 & 100 & 100 & & المجموع \\
\hline
\end{tabular}

يمثل الصدق احد الخصائص المهمة للاختبارات والمقاييس التربوية

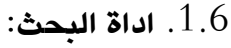
والنفسية ( الجادري وابو حلو ،2009 ، 157 ) ولكي يؤدي الاختبار ماينبني ان يؤديه يجب ان نحصل على اراء الخبراء حوله واقتراح

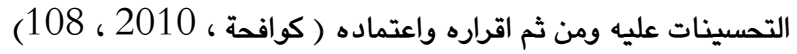
لذا قام الباحث بعرض المقياس بصورته الاولية والمكونة من ( 42 ) فقرة على عدد من المختصين (أ.د. .صابر عبدالله سعيد/قياس و التقويم

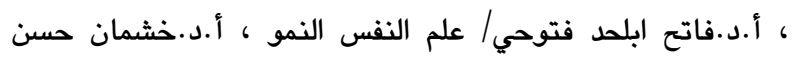
علي/الارشاد و التوجيه، أ.م.د. جاجان جمعة محمد/علم النفس النمو) في العلوم التربوية والنفسية والاستفادة من خبراتهم في مدى صلاحية الفقرة من عدمها ويعد دراسة الخبراء وجد الباحث ان هناك اتفاق بين الخبراء 100\% على صلاحية جميع الفقرات وتم تعديل بعضها لتصبح اكثر ملائمة لمتطلبات البحث فاصبح المقياس متكونا من ( 42 ) فقرة بصيغتها النهائية ولكل فقرة ثلاث بدائل ويذلك ستكون اعلى درجة
لغرض تحقبق هدف البحث قام الباحث ببناء مقياس مهارات التفكير ماوراء المعرفي ولهذا الغرض تم الاطلاع على العديد من الدراسات التي

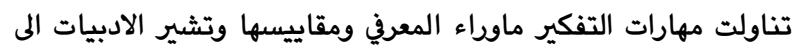
ان هناك عدة تصانيف لمكونات التفكير ماوراء المعرفي الا ان هناك اجماعا بين الباحثين على وجود ثلاث مهارات اساسية وهي المهارات التي وضعها ( ستينبرج ) وهي ( مهارة التخطيط ، مهارة المراقبة

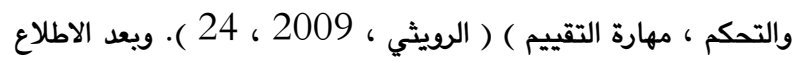
على الادبيات والدراسات السابقة ذات العلاقة بمتفير مهارات التفكير ماوراء المعرفي قام الباحث باعداد ( 42 ) فقرة بصورتها الاولية

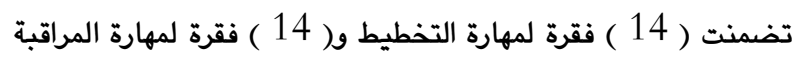
والتحكم و( 14 ) فقرة لمهارة التقييم. 2.6. الصدق الظاهري لمقياس مهارات التفكير ماوراء 
1-الاختبار التائي لعينة واحدة مترابطة ( البياتي ، 1977 ، 260 ) للتعرف على دلالة الفرقق بين المتوسطات المتحققة والاوساط الفرضية

للمتغيرات التي تم قياسها ( مهارات التفكير ماوراء المعرفي ). 2-الاختبار التائي لعينتين مستقلتين.( النبهان ، 2004 ، 249 ، 249 ) مهارات للتعرف على دلالة الفروق بين المتغيرات تبعا للتخصص الدراسي

3- معامل ارتباط بيرسون ( البياتي ، 1977 ، 83 ، ). لحساب ثبات المقياس مهارات التفكير ماوراء المعرفي. 7. عرض النتائج ومناقشتها

1.7. التعرف على مستويات التفكير ماوراء المعريف لدى طلبة

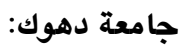
يوضح الجدول(2) ان المتوسط المحسوب لدرجات عينة البحث على مقياس مهارات التفكير ماوراء المعري بلغ(90.63 بدرجة اندوسي ويانحراف معياري (8.4) درجة وعند مقارنته بالمتوسط النظري للمقياس والبالغ (84) درجة وقد تبين ان هناك فرقا واضحا بين المتوسطين ولمعرفة

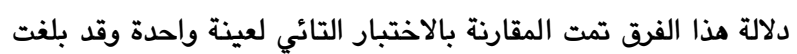
القيمة التائية المحسوية ( 11.23) وهي اعلى من القيمة التائية الجدولية ( 1.96) عند مستوى دلالة 0.05) ودرجة حرية (199) ويدل ذلك على وجود دلالة معنوية لصالح عينة البحث ويشير ذلك الى تمتع طلبة جامعة دهوك بمستوى مرتفع من الوعي بمهارات التفكير

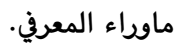

للمقياس ( 126 ) درجة وادنى درجة ( 42 ) درجة والمتوسط الفرضى هو ( 84 ( ) م درجة.

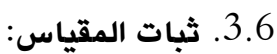
يعني مفهوم الثبات مدى اعطاء الاختبار لنفس الدرجات او القيم للافراد نفسهم اذا ما تكررت عملية القياس عليهم ( عوض ، 1998 ، 193 ، 53 ) وقد تم حساب الثبات بطريقة اعادة الاختبار وقد تكونت عينة الثبات من ( 30 ) طالبا وطالبة من طلبة كلية التربية الاساس ويعد مرود اسبوعين من الاختبار الاول تمت اعادة الاختبار نفسه على العين نفسها ويسمى معامل الثبات بهذه الطريقة بمعامل الاستقرار اي استقرار نتائج الاختبار في الفترة بين التطبيق الاول والثاني للاختبار ( مجيد ، 2010

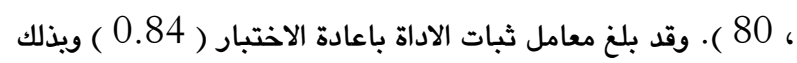

اصبحت الاداة جاهزة للتطبيق. 4.6. تصحيح المقياس

لقد تمت صياغة فقرات المقياس بشكل عبارات تقريرية يسهل الاجابة عليها من قبل عينة البحث ووضعت لكل فقرة ثلاثة بدائل وهي ( تنطبق بدرجة عالية / تنطبق بدرجة متوسطة / تنطبق بدرجة ضعيفة ) واعطيت (3 ) درجات للدرجة العالية و ( 2 ) للدرجة المتوسطة و ( 1 (لدونهو ) درجة للدرجة الضعيفة. وقد تراوحت درجات المقياس بين ( 126 ) درجة كصد اعلى و (42 ) درجة كدد ادنى وكان المتوسط الفرضي للمقياس هو ( 84 م ) درجة. 5.6. الوسائل الاحصائية : استخدم الباحث الوسائل الاحصائية الاتية : الجدول (2): المتوسط المحسوب والانحراف المعياري والقيمة التائية المحسوية لعينة الطلبة على مقياس مهارات التفكير ماوراء المعرفي

\begin{tabular}{rrrrr}
\hline المتوسط المحسوب \\
\hline 1.96 & 11.23 & 84 & 80.63 \\
\hline
\end{tabular}

المعرفي تبين وجود فرق دال معنويا في مجال التخطيط والمراقبة

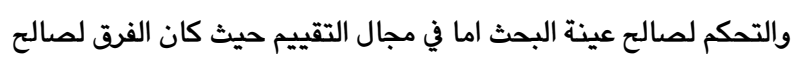
الوسط الفرضي باستخدام الاختبار التائي لعينة واحدة مترابطة عند مستوى دلالة (0.05 ) ودرجة حرية (199) مما يشير الى مستوى عال لمكوني التخطيط والمراقبة والتحكم لدى طلبة الجامعة اما في مجال مهارة التقييم فقد تميزت بانخاض المستوى ملى مليك

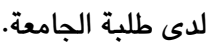

ولغرض التعرف على مستويات مكونات مهارات التفكير ماوراء المعريي

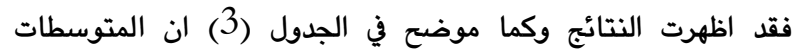
المحسوية والانحرافات المعيارية لعينة البحث وهي مهارة التخطيط

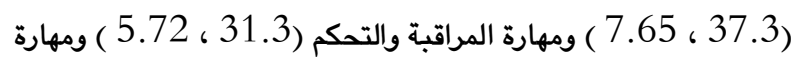

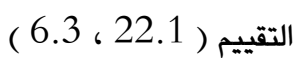
0) (يمثل الرقم الاول المتوسط الحسابي والرقم الثاني الانحراف المعياري ) ومن خلال المقارنة بين المتوسطات المحسوية لدرجة افراد عينة البحث والمتوسط النظري لمكونات مقياس مهارات التفكير ماوراء الجدول (3): المتوسط المحسوب والانحراف المعياري والقيمة التائية المحسوبة لعينة البحث على مهارات التفكير ماوراء المعرفي

\begin{tabular}{|c|c|c|c|c|c|}
\hline القيمة التائية الجدولية & القيمة التائية المحسوية & المتوسط النظري & الانحراف & المتوسط & 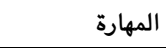 \\
\hline 1.96 & 17.3 & 28 & 7.65 & 37.2 & التخطيط \\
\hline 1.96 & 8.25 & 28 & 5.72 & 31.3 & المراقبة والتحكم \\
\hline 1.96 & 13,1 & 28 & 6.3 & 22.1 & التقييم \\
\hline
\end{tabular}

*مثل الرقم الاول المتوسط الحسابي والرقم الثاني الانحراف المعياري* 
كذلك تبين من الجدول ( 4 ) بان المتوسط المحسوب لدرجات الطلاب على المقياس بلغ ( 84.3 ) درجة وبانحراف معياري ( 10.3 ) وهي اقل من المتوسط المحسوب لدرجات الطالبات في الاقسام العلمية اذ بلغ المتوسط المحسوب لدرجات الطالبات ( 96.8 ) ويانحراف معياري ( 7.5 )وياستخدام الاختبار التائي لعينتين مستقلتين للتعرف على دلالة الفروق وجد ان القيمة التائية المحسوية بلغ ( 20.83 ) وهي اكبر من القيمة التائية الجدولية ( 1.96 ) عند مستوى دلالة ( 0.05 ) ودرجة اندية حرية ( 98 ) مما يشير بان الطالبات في الاقسام العلمية يستخدمن مهارات التفكير ماوراء المعرفي افضل من الطلاب. ويتفق نتائج هذه بـان الدراسة مع دراسة الجراح وقد يعود تفسير ذلك الى ان بعض السمات

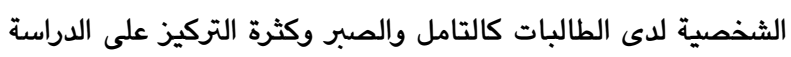
ليصبحن اكثر قدرة على الابداع والتحصيل

2.7. الهدف الثاني /التعرف على دلالة الفروق في مهارات التفكير ماوراء المعرفي حسب الجنس والاختصاص: تبين من الجدول (4)بان المتوسط المحسوب لدرجات الذكور على مقياس مهارات التفكير ماوراء المعرفي بلغ(94.6 )درجة ويانحراف معياري (7.8 ) وهي اكبر من المتوسط المحسوب لدرجات الطالبات اذ كان متوسط الدرجات لديهن على الاختبارقد بلغ (86.3 ) درجة الدئ ويانحراف معياري (9.6 ) وياستخدام الاختبار التائي لعينيتين مستقلتين للتعرف على دلالة الفرق وجد ان القيمة التائية المحسوية

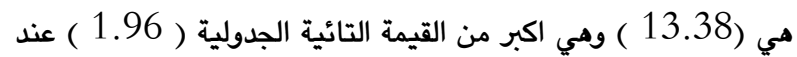
مستوى دلالة ( 0.05 ) ودرجة حرية (98 ) لما يشير بان الطلاب في العلوم الانسانية يستخدمون مهارات التفكير ماوراء المعرفي افضل من دن ودنان الطالبات. وقد يعود ذلك بان الطلاب في العلوم الانسانية اكثر تاملا في الحصول على عل بعض المناصب الادارية والقيادية وهذا يلائم تكوينهم وتطلعاتهم

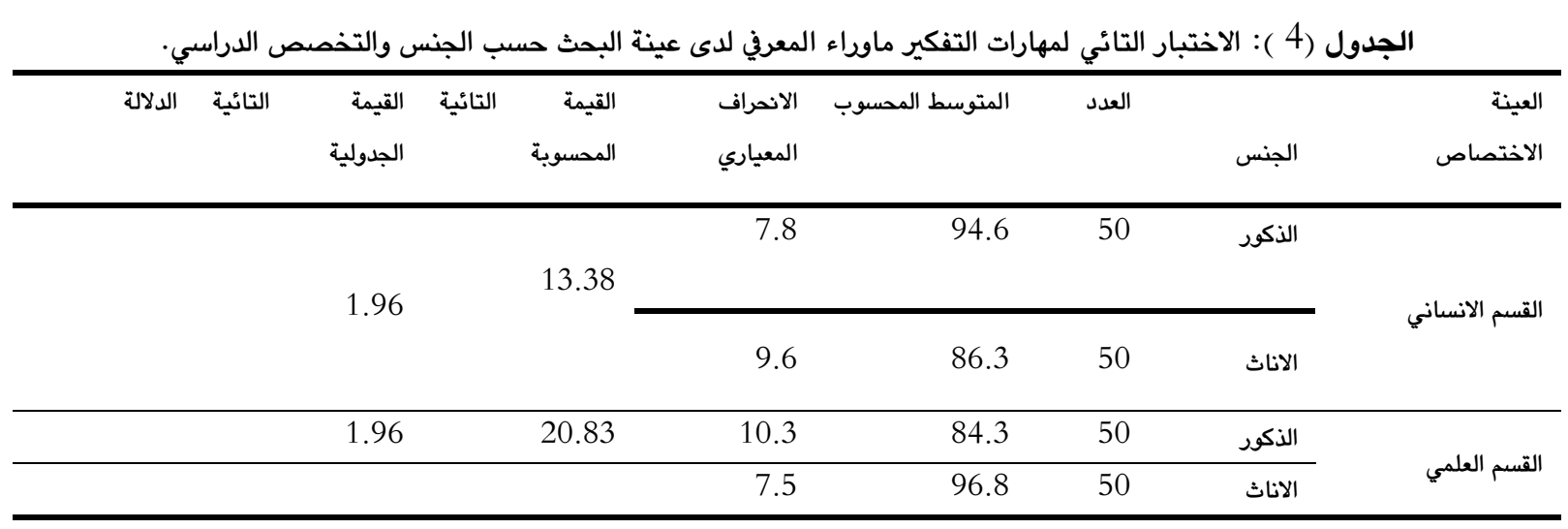

1-ضرورة الاهتمام باطلاع الطلبة على مكونات مهارات التفكير ماوراء المعرفة ويخاصة مهارة التقييم. 2-تشجيع الطلبة على التعرف على مهارات التفكير بشكل عام ومهارات التفكير المعرفي بشكل خاص وتوظيف ذلك في تعاملهم مع مواقف الحياة الاجتماعية والدراسية.

3-ضرورة مساهمة الجامعات والكليات في تنمية مهارات التفكير العليا

المتمثلة بحل المشكلات وكيفية التفكير والتخطيط للعمل والدراسة.

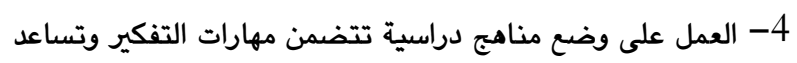
على الابتكار من خلال الاسئلة التي تقيس عمليات التفكير.

\section{10 المقترحات}

على ضوء نتائج البحث يقترح الباحث الدراسات الاتية: 1-مهارات التفكير ماوراء المعرفي وعلاقته بمتغيرات المرحلة الدراسية والموقع الجغرافي. 2-مهارات التفكير ماوراء المعرفي وعلاقته بالذكاءات المتعددة لدى

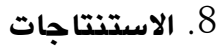

$$
\text { استنتج الباحث مايأتي : }
$$

1-ان طلبة جامعة دهوك يتميزون بالوعي فيما يخص بمهارات التفكير ماوراء المعرفي وهذا مايمكنهم من رفع مستوامم العلمي والاكاديمي وتفاعلهم مع الحياة الجامعية. 2-مهارات التفكير ماوراء المعرفي ( التخطيط والمراقبة والتحكم والتقييم )تمثل مهارات مهمة في مساعدة الطلبة في تعلمهم وتعينهم في ماوراء مواجهة المواقف الحياتية التي تواجههم. 3-ان متغير التخصص والجنس كان له تاثير في تباين الدرجات مما يشير الى الحاجة لاجراء المزيد من البحوث للكشف عن العوامل المؤثرة في تباين الدرجات لدى الطلبة 9. التوصيات على وفق نتائج البحث يوصي الباحث ماياتي : 


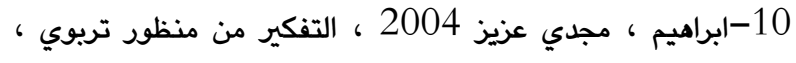

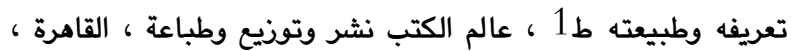
مصر 11-ابو جادو، صالح محمد ونوفل محمد بكر 2010 ، تعليم التفكير النظرية والتطبيق ط4 دار المسيرة للطباعة والنشر ، عمان ، الاردن

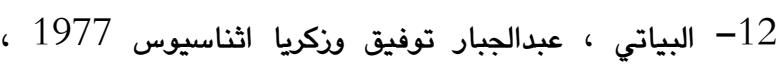
الاحصاء الوصفي والاستدلالي في التربية وعلم النفس ، مطبعة مؤسسة الثقافة العمالية ، بغداد 13-الجراح ، عبدالناصر وعلاء الدين عبيدات 2011 ، مستوى التفكير ماوراء المعرفي لدى عينة من طلبة جامعة اليرموك في ضوء بعض

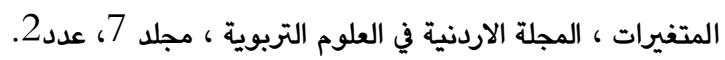
14، مجلة جامعة النجاح للابحاث والعلوم الانسانية ، مجلد 25. 15-الخلي ، ذكرى يوسف عبدالواسع 2008 ، فعالية برنامج حل المشكلات في تنمية مهارات ماوراء المعرفة لدى طالبات الصف السابع الاساسي في مدينة تعز ، كلية التربية ، جامعة صنعاء 16-العتوم ، عدنان يوسف 2004 ، علم النفس المعرفي ، النظرية والتطبيق ، دار المسيرة للنشر والتوزيع ، عمان ، الاردن. 17-العتوم واخرون 2013، تنمية مهارات التفكير نماذج نظرية وتطبيقات عملية ط4 دار المسيرة للنشر والتوزيع ، عمان ، الاردن. 18-العيسوي ، عبدالرحمن محمد 2005 ، الوقاية من الاضطرابات

النفسية وسبل علاجها ،دار ملا للنشر والتوزيع ، القاهرة ، مصر.

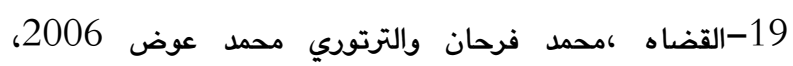
اساسيات في علم النفس التربوي ، النظرية والتطبيق ، دار الحامد للنشر فروي والتوزيع ، عمان ، الاردن. 20-المزروع ، هيا 2005 ، استراتيجية شكل البحث الدائري وفاعليتها في تنمية مهارات ماوراء المعرفة لدى طالبات المرحلة الثانوية ذوات السمات العقلية المختلفة ، مجلة رسالة الخليج العربي العدد 96 الرياض ، المملكة العربية السعودية. 21-المساعيد ، اصلان صبح ، الريمل العربية 2008 ، تطوير مقياس لمهارات ماوراء المعرفة ، مجلة جامعة الملك سعود للعلوم التربوية والاسلامية م

22 - الجادري ، عدنان حسين وابو حلو يعقوب 2009 ، الاسس المنهجية والاستخدامات الاحصائية في بحوث العلوم التربوية والانسانية ، اثراء للنشر والتوزيع ، عمان ، الاردن.

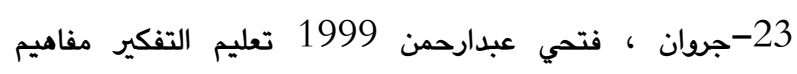
وتطبيقات ط1 ، دار الكتاب الجامعي ، العين ، الامارات العربية المتحدة. 24-حميدة ، اماني مصطفى السيد 2010 التساؤل الذاتي والمتشابهات ، جامعة عين شمس ، القاهرة ، مصر.9 9
3-مهارات التفكير ماوراء المعرفي وعلاقته ببعض السمات الشخصية لدى طلبة المرحلة الاعدادية.

4-مهارات التفكير ماوراء المعرفي وعلاقته بالسيطرة المعرفية لدى

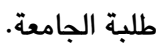
5-اثر برنامج تعليمي في تنمية مهارات التفكير ماوراء المعرفي لدى طلبة

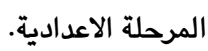

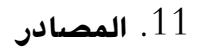

1- اسماعيل ، بليخ حمدي 2013 ، استراتيجيات تدريس اللغة العربية ، اطر نظرية وتطبيقات عملية ط1 1 ، دار المنامج للنشر والتوزيع

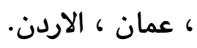
2- النجدي ، احمد واخرن 2005 ، اتجاهات حديثة لتعليم العلوم في ضوء المعايير العالمية وتنمية التفكير ط1 ، دار الفكر العربي ، القاهرة ، مصر. 3- خطاب ، احمد علي ابراهيم 2007 ، اثر استراتيجية ماوراء المعرفة في تدريس الرياضيات على التحصيل وتنمية التفكي الابداعي لدى تلاميذ الحلقة الثانيةمن التعليم الاساسي ، رسالة ماجستير غير الدير منشورة ، كلية التربية ، جامعة الفيوم. 4- سيد ، امام مصطفى والشريف صلاح الدين 1999 ، ماوراء الذاكرة والحمل العقلي وعلاقتها بالتحصيل الاكاديمي لدى طلبة كلية

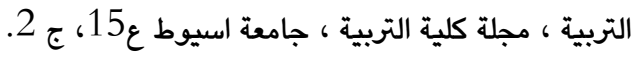
5- عثامنة ، شيرين عوض 2008 ، اثر برنامج تدريبي مستند الى كلى علية

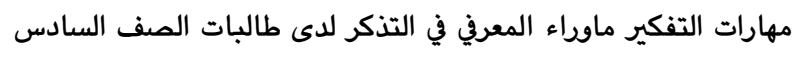
الاساسي بمديرية تربية اربد الثانية ، رسالة ماجستير غير منشورة ، كلية التربية ، جامعة اليرموك ، الاردن. 6- عفيفي ، منال شمس الدين احمد 2006 ، علاقة مكونات ماوراء الذاكرة والتوجهات الدافعية بالتحصيل الدراسي، رسالة ماجستير غير منشورة ، كلية التربية بالاسماعيلية ، جامعة قناة السويس. 7- عوض ، عباس محمود 1998 ، القياس النفسي بين النظرية والتطبيق ، دار المعرفة الجامعية ، القاهرة ، مصر - مجيد ، سوسن شاكر 2010 ، الاختبارات النفسية ، دار صفا للنشر والتوزيع ، عمان 6 الاردن 8- قطامي ، يوسف 2005 ، النظرية المعرفية في التعلم ط1 ، دار المسيرة للنشر والتوزيع والطباعة ، عمان ، الاردن.

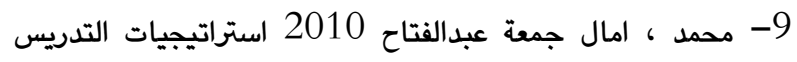
والتعليم ، نماذج وتطبيقات ، دار الكتاب الجامعي ، العين ، الامارات العربية المتحدة. 
35-كوافحة ، تيسير مفلح 2010 ، القياسوالتقييم واساليب القياس

والتشخيص في التربية الخاصة ، دار المسيرة للنشر ، عمان ، الاردن 36-يوسف ، سليمان عبدالواحد 2011 ، الفروق الفردية في العمليات العقلية والمعرفية ط11، دار المسيرة للنشر والطباعة ، عمان ، الاردن. 37- السبعاوي ، احمد محمود صالح عبدالله 2013 ، اثر استراتيجية التساؤل الذاتي في تنمية مهارات التفكير ماوراء المعرفي لدى تلاميذ المرحلة الابتدائية ، رسالة ماجستير غير منشورة ، كلية التربية الاساسية ، جامعة الموصل. 38- العتوم ، عدنان يوسف واخرون 2007 ، تنمية مهارات التفكير ، نماذج نظرية وتطبيقات عملية ، دار المسيرة للنشر والتوزيع ، عمان،

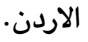
39- العلوي ، ضحى محمد جبر ، 2012 ، اثر استراتيجية التدريس التبادلي في التحصيل وتنمية مهارات التفكير ماوراء المعرفي لدى طالبات الرابع الادبي ، رسالة ماجستير غير منشورة كلية التربية ، ابن رثد جامعة بغداد. 40- العيسوي ، عبدارحمن محمد 2008 ، الوقاية من الاضطرابات

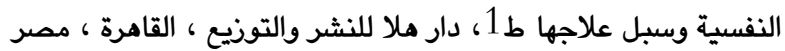
41- النبهان ، موسى 2004 ، اساسيات القياس في العلوم السلوكية ط1 ، دار الشروق للنشر والتوزيع ، عمان ، الاردن. 42-Brown, A.L \& Barclay , C.R 1976, The Effects of Training Specific Mnemouics on the MetamemouicEficiency of Retarded children ,child development 47,71,80.

43-Flavell,T,H,1976,Metacognative Aspects of problem solving.The Nature of Intelligence. Hillsdale ,NJ ,Erlbaum 'pp231-235'.

44-Moses, L,J, \& Baird ,j,1996, Metacognation ,M11,Encyclopedia of cognative ,available.

45-Perkins,D 1992, Smart schools For Training Mmories to Educational Minds. New York Mac Millan, inc.
25-دسوقي ، محمد احمد 1990 ، مشكلات طلاب كلية التربية وحاجاتهم الارشادية ، مجلة كلية التربية ، جامعة الزقازيق عدد 12

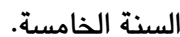
26-ردادي ، زين بن حسن 2002، المعتقدات المعرفية واستراتيجيات التنظيم للتعلم الذاتي وعلاقتها بالتحصيل الدراسي لدى تلاميذ مدارس منارات المدينة ، مجلة كلية التربية. جامعة الزقازيق

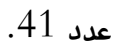
27- الرويثي ، ايمان محمد احمد 2009 ، رؤية جديدة في التعلم والتدريس من منظور التفكير فوق المعرفي ط1 دار الفكر ، عمان ، الاردن 28-سيد ، امام مصطفى والشريف صلاح الدين حسين 1999 ، ماوراء الذاكرة استراتيجيات التذكر واساليب الاستذكار والحمل العقلي وعلاقتها بالتحصيل الاكاديمي لدى طلاب كلية التربية ، مجلة كلية

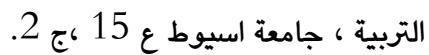
29-الشرقاوي ، انور محمد 2003 ، علم النفس المعرفي المعاصر ط2 مكتبة الانجلو المصرية ، القاهرة.

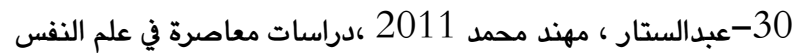
المعرفي ط1، دار غيداء للنشر والتوزيع ، عمان ، الاردن. 31-عبيد ، وليم 2009 ، استراتيجيات التعليم والتعلم في سياق ثقافة ، الجودة ط11، دار المسيرة للطباعة والنشر ، عمان ، الاردن. 32-عفانة ، عنو ونشوان تيسير 2010 ، اثر بعض استراتيجيات ماوراء المعرفة في تدريس الرياضيات على تنمية التفكير المنظومي لدى طلبة الصف الثاني الاساسي بغزة ، انترنيت. K.W.L الحافظ ، هبة محمد صالح 2011 ، اثر استراتيجية في تنمية عمليات العلم لدى طالبات الصف الثاني المتوسط في مادة الكيمياء ، رسالة ماجستير غير منشورة ، كلية التربية الاساسية ،

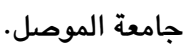
34-عفيفي،منال شمس الدين احمد 2006 ، علاقة مكونات ماوراء الذاكرة والتوجهات الدافعيةبالتحصيل الدراسي ، رسالة ماجستير غير منشورة كلية التربية بالاسماعيلية ، جامعة قناة السويس. 
ملحق ( 1 ): مقياس مهارات التفكير ماوراء المعرفي بالصيغة النهائية

\begin{tabular}{|c|c|c|c|c|}
\hline | تنطبق علي بدرجة ضعيفة & | تنطبق علي بدرجة متوسطة & | تنطبق علي بدرجة عالية & | ارة التخطيط & ت \\
\hline & & & اضع I هدافا تمكنني من النجاح قبل البدء بالمهام الدراسية & .1 \\
\hline & & & استخدم بعض الرموز والاشارات عند القراءة للمواد الدراسية & .2 \\
\hline & & & اضع خطة في كيفية القيام بالدراسة في بداية العام الدراسي & .3 \\
\hline & & & انضم وقتي قبل بالبدء بالدراسة لكي احقق اهدافي الدراسية & 4 \\
\hline & & & | اخصص وقتا كافيا لكل مادة دراسية يناسبها & .5 \\
\hline & & & اراجع نفسي باستمرار لكي اتمكن من تحقيق اهدافي الدراسية & .6 \\
\hline & & & | احاول ربط ما اقراه بالمعلومات التي امتلكها & .7 \\
\hline & & & اضع عدة اسئلة اثناء الدراسة لتساعني على فهم الموضوع & .8 \\
\hline & & & | اقرا ملاحظات الاسئلة واتاكد منها قبل البدء بالاجابة عنها & .9 \\
\hline & & & | اتاكد من جودة اداتي عندما اتعلم شيئًا جديدا & .10 \\
\hline & & & | احاول التعرف على الافكار الرئيسية في موضوع الدراسة & .11 \\
\hline & & & |عرف الحلول المناسبة للمشكلات التي تواجهني اثناء الدراسة & .12 \\
\hline & & & |ستخدم الصود والاستيراتيجيات لمساعدتي على فهم المواد الدراسية & .13 \\
\hline & & & اسال نفسي فيما قد اخذت بجميع الاختبارات لحل مشكلات الدراسية & .14 \\
\hline \multirow[t]{15}{*}{ | تنطبق علي بدرجة ضعيفة } & تنطبق علي بدرجة متوسطة & تنطبق علي بدرجة عالية & مهارة المراقبة والتحكم & $ت$ \\
\hline & & & | لبعد انتهاء الدرس اسال نفسي فيما تعلمت شيئاً جديدا & .1 \\
\hline & & & | احاول التعرف على اجابات الاسئلة التي أخطأت فيها. & .2 \\
\hline & & & | اتذكر المعلومات المنظمة أكثر من غيرما. & .3 \\
\hline & & & يمكنني ان اتذكر المعلومات والحقائق المهمة اكثر من غيرها. & .4 \\
\hline & & & | احافظ على الخطوات المنظمة التي وضفتها لحل مشكلات الدراسية. & .5 \\
\hline & & & | احاول على تركيز انتباهي اثناء سير المحاضرة الدراسية. & .6 \\
\hline & & & | افضل الجلوس في المكان المناسب في الصف وقت شرح الدرس. & .7 \\
\hline & & & | اقوم بتسجيل الملاحظات المهمة اثناء المحاضرة. & .8 \\
\hline & & & | اتوقع لاكثر من سؤال قد يضعه المدرس للامتحان & .9 \\
\hline & & & | لدية القابلية على التغلب على الصعويات التي تواجهني. & .10 \\
\hline & & & | احاول اعادة دراسة المعلومات الجديدة التي لم تكن واضحة لدية & .11 \\
\hline & & & | اتامل من وقت لاخر لكي افكر في صحة المعلومات التي درستها. & .12 \\
\hline & & & | احاول الوصول الى معرفة معاني الاشياء المبهمة علي في الفهم. & .13 \\
\hline & & & | لـصص وقتا للراحة اذا ما شعرت بالتعب اثناء الدراسة & .14 \\
\hline \multirow[t]{15}{*}{ تنطبق علي بدرجة ضعيفة } & | تنطبق علي بدرجة متوسطة & | تنطبق علي بدرجة عالية & 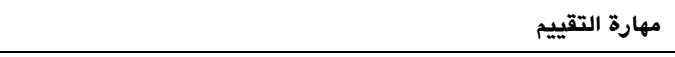 & ت \\
\hline & & & أقيم ادائي باستمرار لمعرفة مدى ماحققه من اهدافي الدراسة & .1 \\
\hline & & & احاول تكوين صورة ذهنية متكاملة بعد قراءتي للموضوع الدراسي & .2 \\
\hline & & & اتاكد من دقة الاعتبارات والامكانات الملائمة لحل المشكلات & .3 \\
\hline & & & بامكاني تحديد مواطن الضعف اثناء قيامي بالدراسة & .4 \\
\hline & & & اتساءل حول مناسبة اسلوبي للتعلم الجيد & .5 \\
\hline & & & باستطاعتي تخمين درجاتي بعد الانتهاء من اداء الامتحان & .6 \\
\hline & & & حينما اكون غير راضيا عن ادائي احاول ان اتعلم الاداء الافضل & .7 \\
\hline & & & عندما اقرا احاول الوصول الى مستوى الفهم الجيد ع & .8 \\
\hline & & & اطلب مساعدة المدرس عندما اجد نفسي عاجزا عن فهم المحاضرة & .9 \\
\hline & & & بامكاني تلخيص ماتعلمته بعد الانتهاء من الدرس & .10 \\
\hline & & & احدد الوقت المناسب الذي امضيه في فهم الدرس & .11 \\
\hline & & & اضع مقارنة بين ادائي واداء زملائي في الصف & .12 \\
\hline & & & لدى القدرة على التمييز بالمواضيع السهلة والصعبة في المصادر الدراسية. & .13 \\
\hline & & & لدي القدرة على شرح موضوع الدرس امام زملائي الطلبة & .14 \\
\hline
\end{tabular}




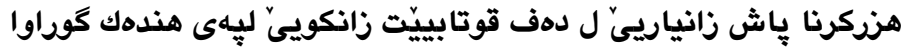

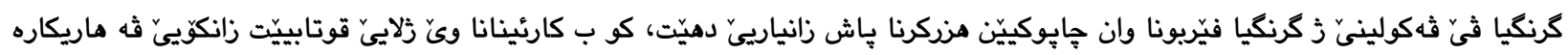

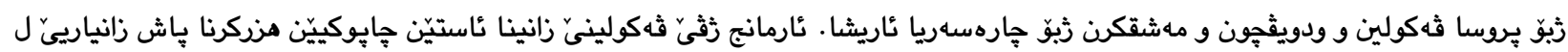

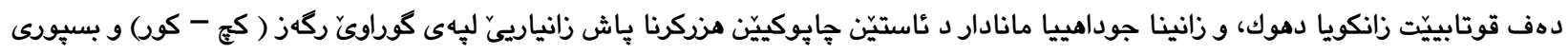

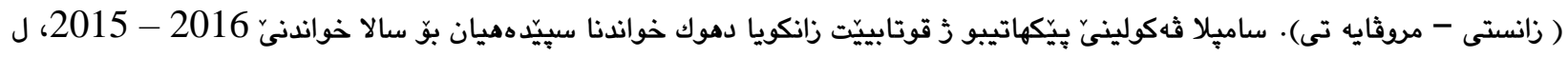

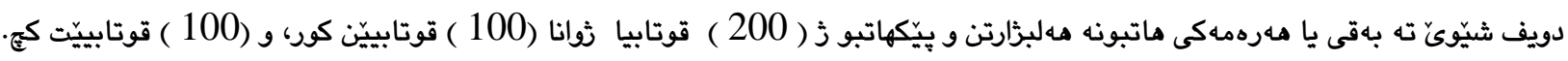

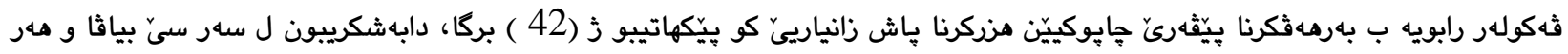

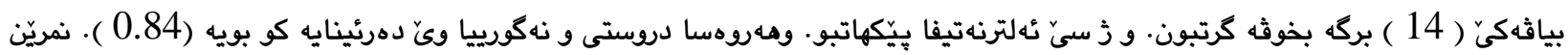

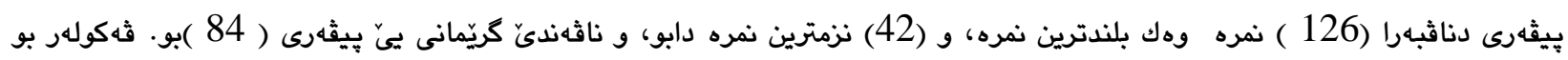

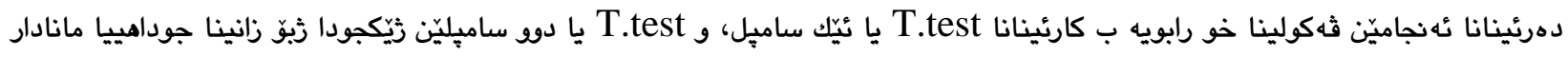

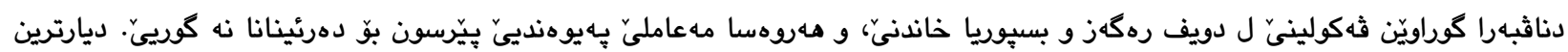

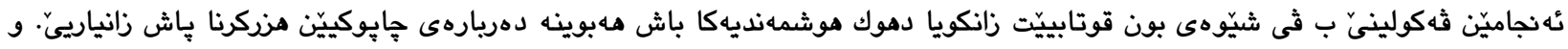

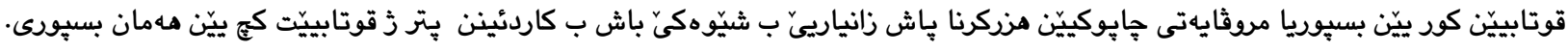

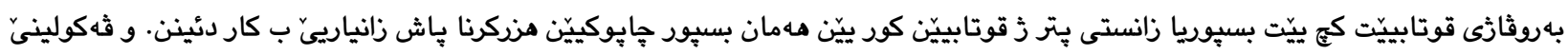

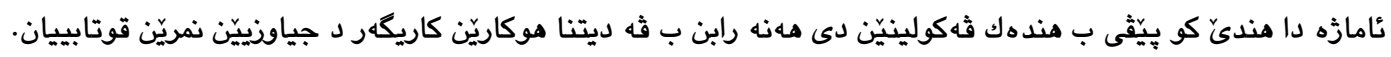

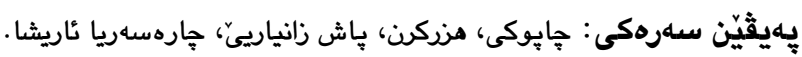

\section{Metacognitive Thinking by University Students and its Relationship with Some Variables}

\section{Abstract:}

The importance of the research comes through the importance of learning the skills of Meta cognitive thinking as it contributes when it is used by university students for research investigation and training to solve the problems. The research aimed to recognize the level of metacognitive thinking of Duhok university student's band to recognize the differences in abstract concepts in the levels of the metacognitive thinking skills according to gender distinction (male/ female) and specialist (scientific/human). The research in limited with the morning classes of Duhok University student for the academic year 2015-2016. The study contained a sample of (200) students taken randomly (100) male and (100) female. According to the instrument of the research; the researcher adopted a scale of the metacognitive thinking skills which consisted of (42) items distributed on three domains; for each domain (14) items and for every item (3) substitutions. Honesty and constancy of the instrument was found out which was (0.84).

The maximum degrees of the scale were (126) and the minimum were (42) degrees whereas the hypothetical scale was (84) degrees. The researcher used the t-test for one sample t-test for two independent samples to recognize the distinctive concepts between the research differences due to gender and specialty and Pearson correlation to calculate constancy. And the most prominent result of the research was; the students of Duhok University, they are distinguished in awareness that is related to the metacognitive thinking skills.

And the students (male) of human sciences use the metacognitive thinking skills better than female students; meanwhile the female students in scientific application departments use the metacognitive thinking skills better than male students.

Also, the study mentioned the need for more researches to discover the effected factors of students marks contrast. $\square$

Keywords: skill, Thinking, Metacognitive, Problem solving. 